\title{
STUDIES OF RADIOIRON UTILIZATION AND ERYTHROCYTE LIFE SPAN IN RATS FOLLOWING THERMAL INJURY ${ }^{1}$
}

\author{
By WILLIAM M. DAVIS, EDWARD L. ALPEN, AND A. K. DAVIS \\ (From United States Radiological Defense Laboratory, San Francisco, Calif.)
}

(Submitted for publication April 19, 1954; accepted September 3, 1954)

The anemia which develops following thermal burns and the occurrence of a continuing anemia in burned patients and animals has been a frequent finding (1-4). Studies in this laboratory have indicated that in burned rats there is a rapid reduction in circulating red cell volume following high intensity radiant energy thermal burns (4). This reduction in red blood cell volume is followed by a period of increased red cell production as shown by the return of the circulating red cell volume to normal and by a significant reticulocytosis. Clinical studies in severely burned patients $(2,3)$ have revealed evidence of an immediate reduction in the circulating red cell volume and frequently a continuing reduction of the red cell volume.

The studies of Moore, Peacock, Blakely, and Cope (1) in three burned patients and of Wintrobe and his co-workers (5) in two burned pigs showing depressed utilization of radioiron are the only reports of the role of iron metabolism in burn anemia. Reported here are measurements of utilization of tracer doses of radioiron $\left(\mathrm{Fe}^{\mathrm{sg}}\right)$ in the production of erythrocytes, and measurements of erythrocyte life span with $\mathrm{Fe}^{58}$.

\section{METHODS}

Six-week-old female albino rats of the Sprague-Dawley strain from the Laboratory colony were used. These rats weighed between 140 and $180 \mathrm{gm}$. at the time of burning. They were housed in individual wire cages and allowed free access to Purina chow and water. All animals were depilated by the method of Kuhl, Sheline, and Alpen (6). They were anesthetized with Nembutale sodium (4.5 mg. per $100 \mathrm{gm}$. body weight subcutaneously) 4 days later and burned with a high intensity carbon arc source (7) by a method previously described. The burns produced were approximately 25 per cent of the total body area, and were similar, grossly and histologically, to the "white" burn described by

1 The opinions or assertions contained herein are those of the writers and are not to be construed as official or reflecting the views of the Navy Department or the Naval Establishment at large.
Sheline, Alpen, Kuhl, and Ahokas (7). After two to three weeks the gray leathery eschar separated, leaving a raw, relatively clean, partially re-epithelialized area. Further epithelialization occurred in the next six to ten weeks so that by the end of the observation period ( 90 days) the burn areas had healed. Superficial infection of the lesion was a usual finding, but no significant surface loss of blood or fluid was observed.

Days 2, 7 and 15 after burning were selected for studies of utilization of tracer doses of radioiron. On these days a similar number of depilated control rats were prepared which were anesthetized and similarly treated except for burning.

At the appropriate time after burning, each animal was given a standard dose of $0.6 \mathrm{ml}$. of a sodium citrate buffered $\mathrm{FeCl}_{2}$ solution, which contained 3 to $10 \mu \mathrm{c}$. of $\mathrm{Fe}^{\omega}$ in approximately 6 to $20 \mu \mathrm{g}$. of total iron. The amount of radioactivity and the specific activity of the injected iron was the same for each group but varied among the various experimental trials. The $\mathrm{Fe}^{\infty}$ used was $\mathrm{Fe}^{\infty} \mathrm{Cl}_{2}$ obtained from Oak Ridge National Laboratory and contained less than 10 per cent of $\mathrm{Fe}^{\mathrm{w}}$. The tracer dose was injected into the surgically exposed external jugular sinus. The surgical wound was closed with skin clips and healed promptly. Blood samples were taken at six hours and days 1, 2, 3, 5, and 7 following injection of the tracer and at weekly intervals thereafter. Blood samples were drawn by cardiac puncture or external jugular vein puncture through the intact skin. Samples of approximately $0.3 \mathrm{ml}$. of whole blood were taken during the first week; thereafter the samples were 0.1 to $0.2 \mathrm{ml}$. of whole blood. Twenty-five $\mu \mathrm{l}$. of whole blood was plated on cupped planchets in duplicate. Plasma was obtained by centrifugation of blood immediately after withdrawal of the blood, and $25 \mu$. amounts were plated in duplicate on planchets. Hematocrits were performed in duplicate in thick-walled, uniform-bore capillary tubes, sealed with mercury and beeswax and spun for 30 minutes at 3000 RPM in a refrigerated centrifuge at $5^{\circ}$ to $10^{\circ} \mathrm{C}$. The packed red cell and plasma columns were read with a $10 \mathrm{~cm}$. scale.

Radioactivity was measured with an end window scintillation counter. An automatic sample changer, scaler, and automatic timing device were used, and each set of duplicate planchets was counted to a counting. error of 0.5 per cent. The over-all counting efficiency was approximately 4 per cent. At the point of maximum utilization of the injected $\mathrm{Fe}^{\infty}, 25 \mu$. samples gave counting rates approximately 10 to $\mathbf{5 0}$ times background. At the conclusion of the experiment when circulating radio- 
activity had stabilized at minimal values, counting rates (50 or $100 \mu 1$. samples) were approximately 2 to 5 times background.

Radioactivity of the total circulating whole blood was calculated using an estimated blood volume. A large body of observations have been made in this laboratory using the $P^{*}$ method (4) in both control and burned rats of similar age and strain. These values were used for blood volume calculated on a weight basis for given days after burning. Red cell volumes and plasma volumes were calculated using the hematocrit determined from jugular or cardiac blood. Total circulating red cell radioactivity was obtained by subtracting total circulating plasma radioactivity from total circulating whole blood radioactivity. It was found that after 24 hours the plasma had been cleared of essentially all $\mathrm{Fe}^{\mathbf{m}}$ in both control and burned animals and that the measured radioactivity was confined to the circulating red cells. For this reason only whole blood samples were counted beyond the first week. Since with a given measured tracer injection dose an identical measured injection dose standard was prepared and was counted simultaneously with the blood samples, it was unnecessary to correct for decay of radioactivity. However, because of multiple blood sampling of each animal it was necessary to correct for removed radioactivity.

The same animals were kept under observation and utilized for studies of mean erythrocyte life span by the method of Finch, Wolff, Rath, and Fluharty (8) and Burwell, Brickley, and Finch (9). Starting on the seventh day after injection of the tracer dose of radioiron, each rat was given a weekly intravenous injection of $0.4 \mathrm{ml}$. of non radioactive saccharated iron oxide containing $8 \mathrm{mg}$. of inorganic iron. Weekly injections were continued for 10 weeks, at which time circulating radioactivity had stabilized at minimal levels in each animal. A total of $80 \mathrm{mg}$. of iron was given to each animal. In the studies of erythrocyte life span weekly samples were drawn by cardiac or external jugular puncture just prior to each weekly intravenous injection of saccharated iron oxide. Sampling was continued until circulating radioactivity had stabilized (usually between 5 and 15 per cent of the injected radioactivity). A separate control group of five animals, identical except that the weekly intravenous injections of saccharated iron oxide were omitted, was also followed. This group was studied for the purpose of ascertaining the extent to which iron loading inhibits the reutilization of $\mathrm{Fe}^{\mathrm{w}}$.

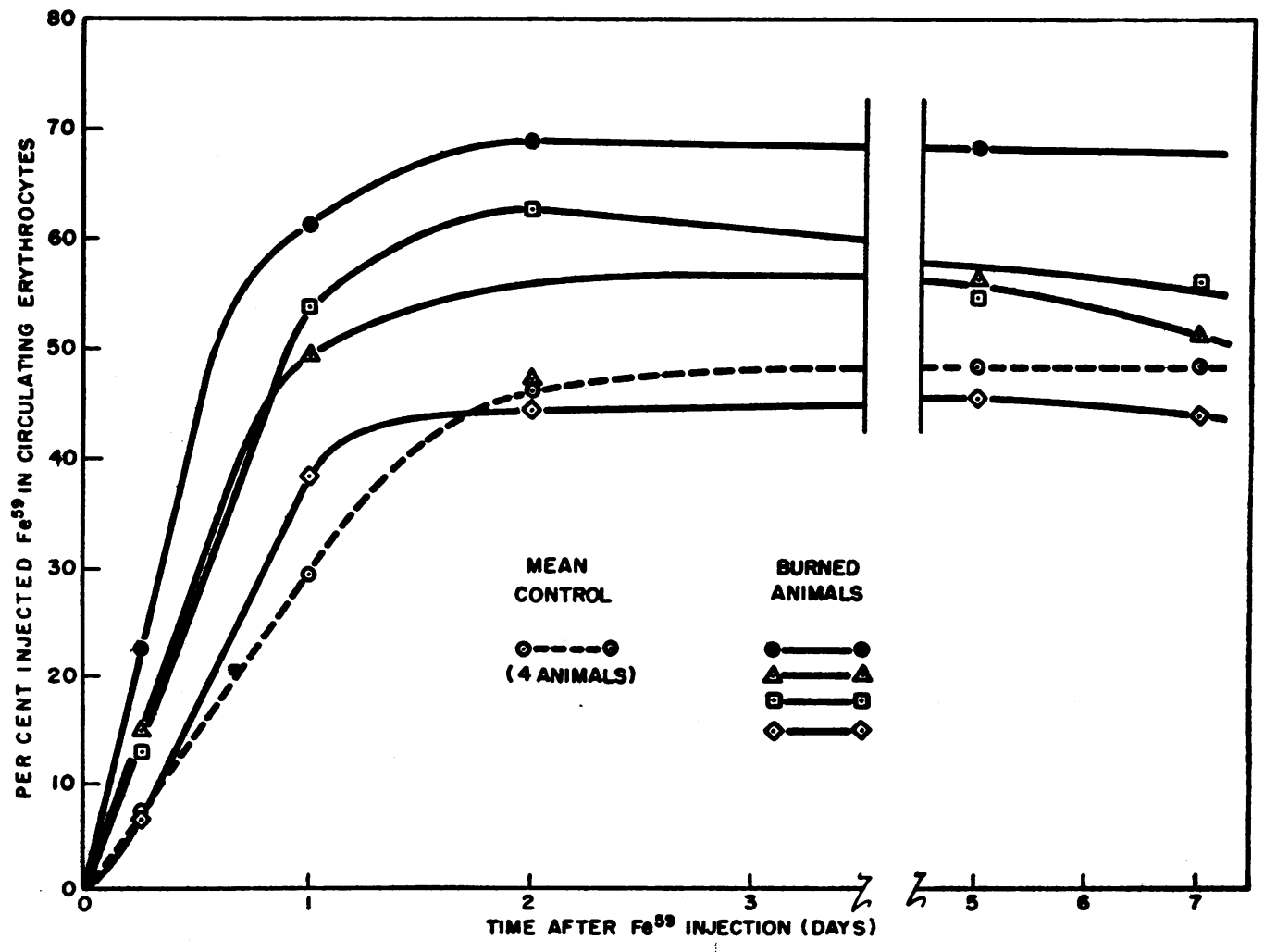

Fig. 1. Utmization of Fe" in Four Burned Anmals Injected with Fe Two Days after Burning, Compared with the Mran Uptake of Fe for Four Control Anmals Run SmulTANEOUSLY 


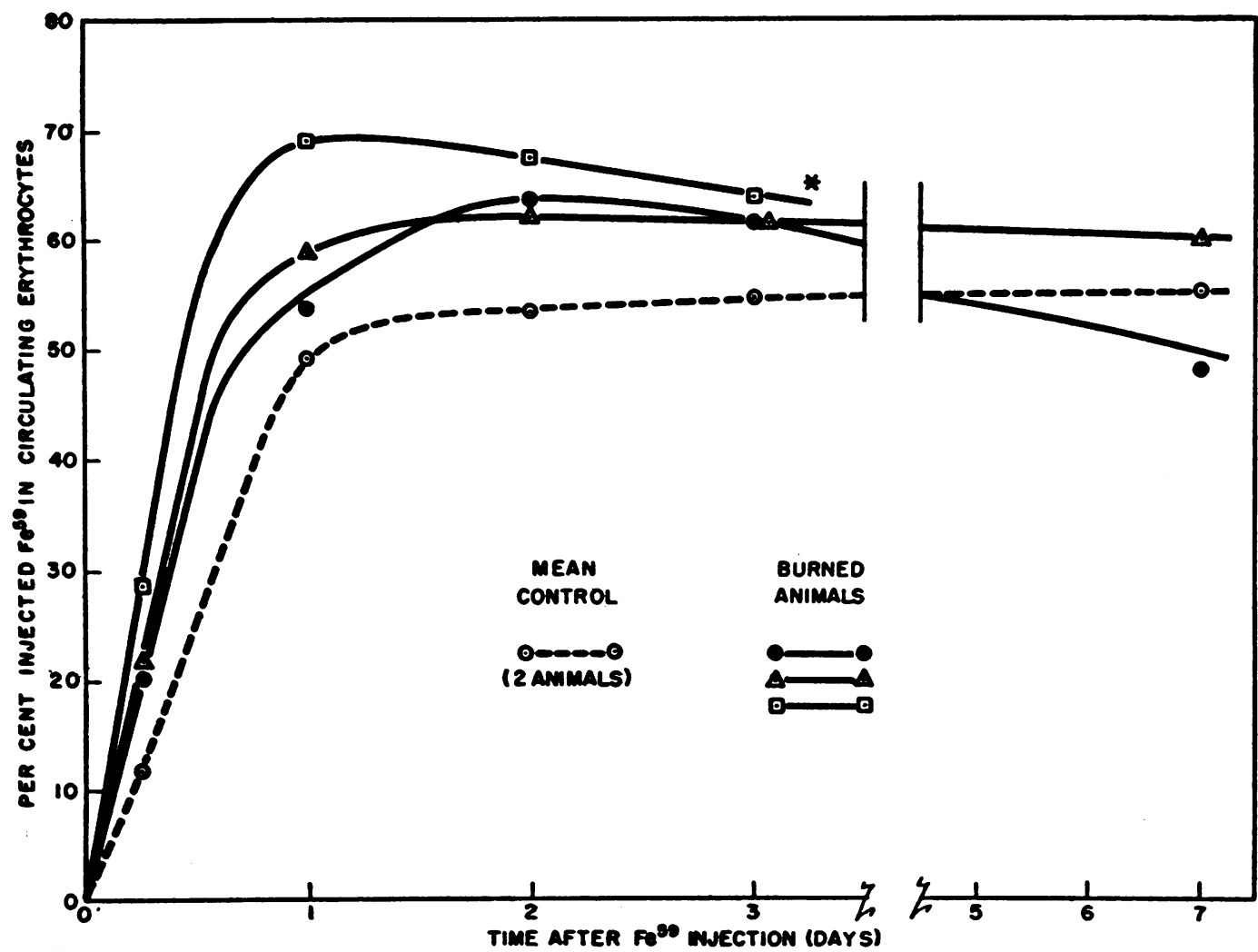

Fig. 2. Utilization of Fe" in Three Bureded Anmcals Injected with Fe" Seven Days after Burning, Compared with the Mean Uptake of Fe for Two Control Animals Run SimulTANEOUSLY

\section{RESULTS}

\section{Utilization of tracer doses of $F e^{\text {so }}$}

Figures 1,2, and 3 indicate the utilization of $\mathrm{Fe}^{\mathrm{s0}}$ in control and burned rats for seven days following injection of a tracer dose of $\mathrm{Fe}^{50}$. The rate of uptake of $\mathrm{Fe}^{50}$ in burned rats was studied commencing on the second, seventh, and fifteenth day following burning. The uptake was found to be more rapid and the fraction of the injected dose of radioiron appearing in red cells was greater than in control animals at 24,48 , and 72 hours after injection of the radioisotope. Moreover, for the 7-day and 15-day groups at the end of one week, the per cent incorporation in the erythrocytes of both control and burned rats tended to approach a common value in the range of 50 to 60 per cent. The group of burned animals studied two days after burning showed a somewhat greater variation in uptake than animals studied at later times after burning. However, the per cent of the injected dose incorporated was still higher than control values at one week after injection.

\section{Measurement of mean erythrocyte life span}

In Figures 4, 5, and 6 are plotted curves of the total radioactivity in red cells of peripheral blood remaining at various times following initial uptake of $\mathrm{Fe}^{\mathrm{sp}}$. These figures are for studies of survival started with injection of $\mathrm{Fe}^{39}$ on days 2,7 , and 15 after burning, respectively. The mean erythrocyte life span is estimated by measuring the time in days required for the total radioactivity to decrease to one-half its maximum value. It is necessary in these calculations to correct for the 5 to 15 per cent of radioactivity remaining at the stabilized low level eventually reached (Figure 7). The data are therefore plotted by subtracting the stable residual activity from the measured value and plotting these corrected values in terms of per cent of the maximum radioactivity attained. 


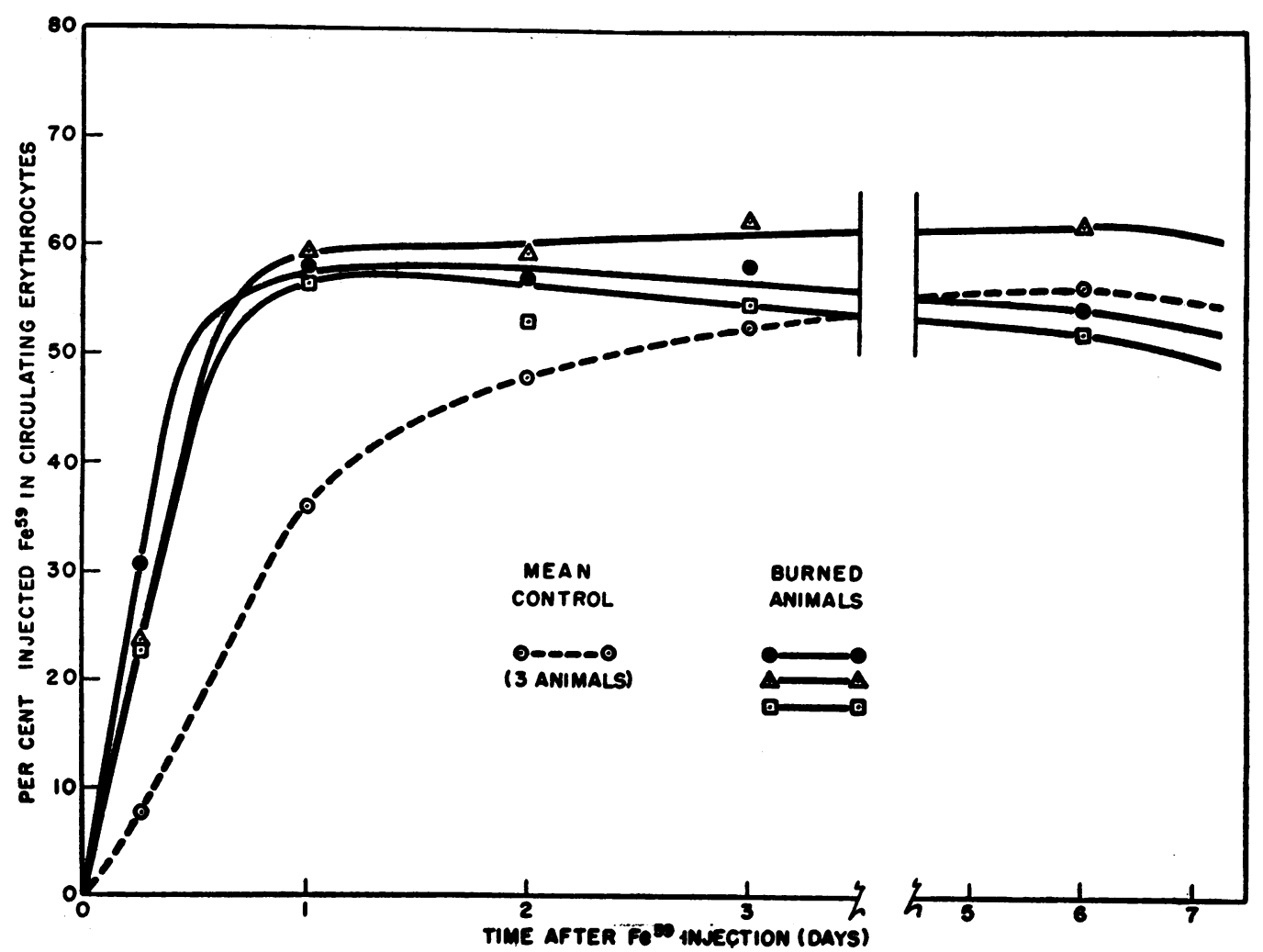

Fig. 3. Utmlization of Fe in Threz Burned Anmals, Injected with Fe 15 Days atter Burning, Compared with the Mean Uptake of Fe" for Three Control animals Run SimulTANEOUSLY

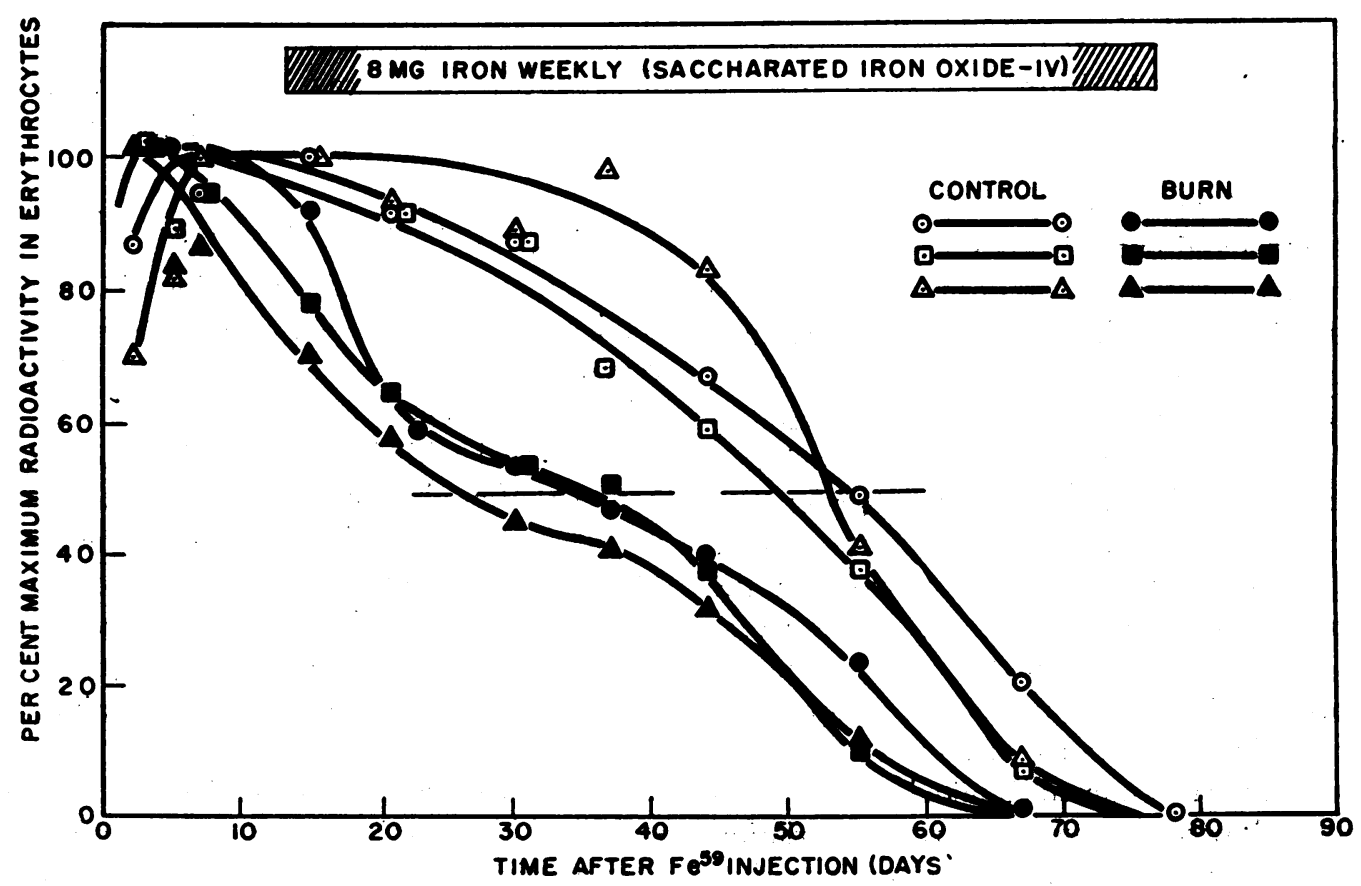

Fig. 4. Erythrocyte Life Span in the Rat. Survival of Tagged Erythrocytzs in Thref Control Animals and Three Burned Animals, Study Begun Two Days Following the Burn 


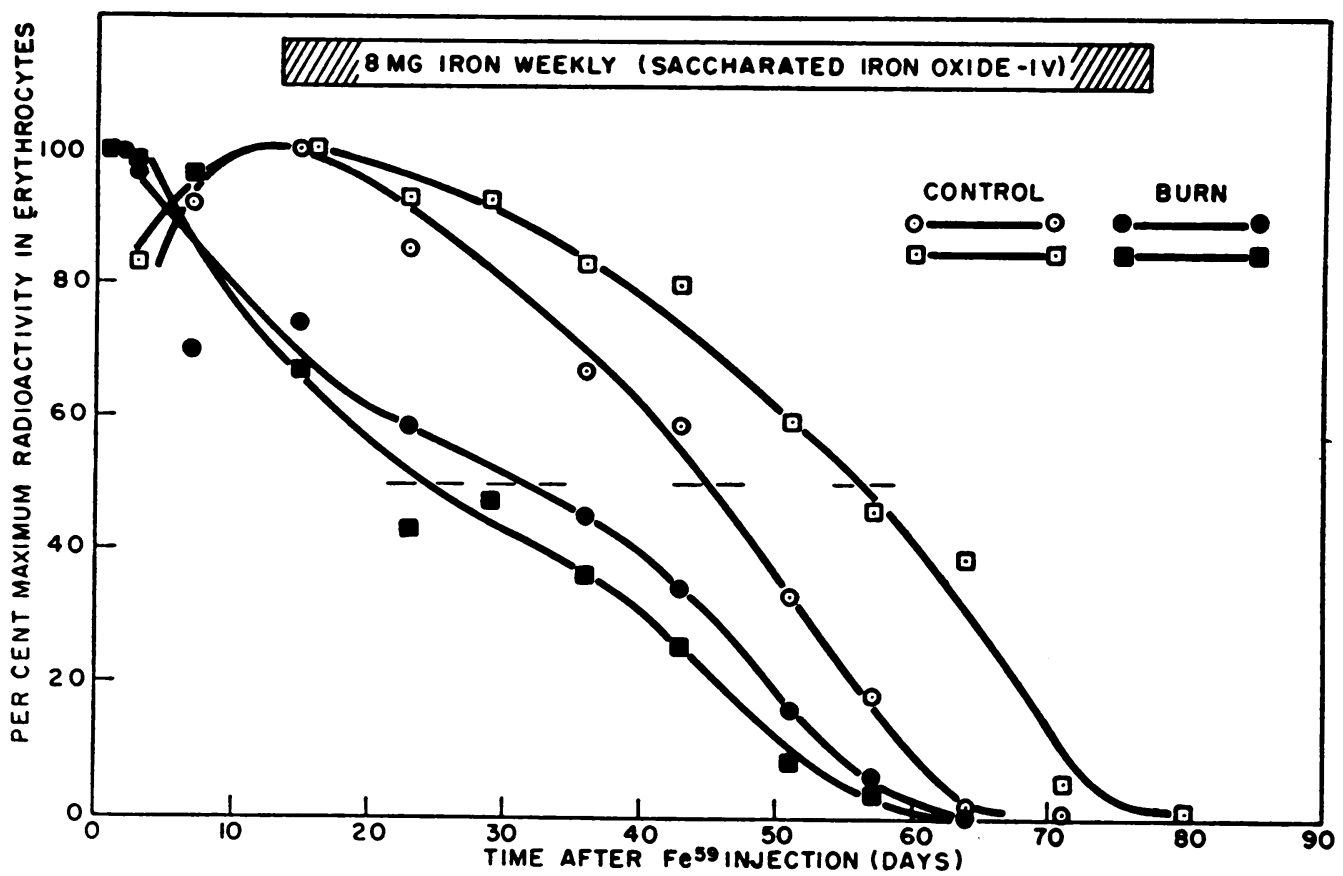

Fig. 5. Erythrocyte Life Span of the Rat. Survival of Tagged Erythrocytes in Two Control Animals and Two Burned Animals, Study Begun Seven Days Following the Burn

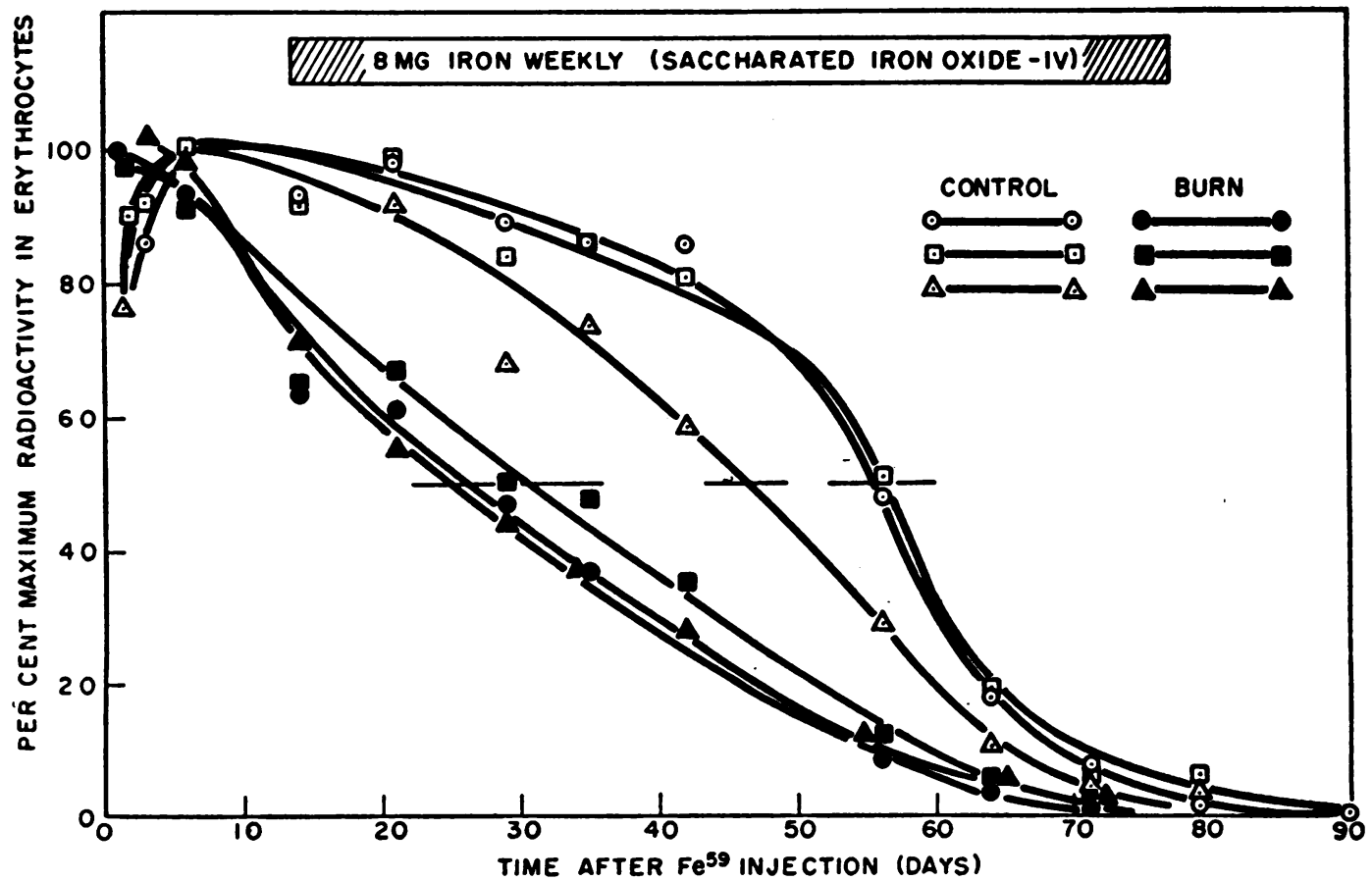

Fig. 6. Erythrocyte Life Span of the Rat. Survival of Tagged Erythrocytes in Thref Control Antmals and Three Burned Animals, Study Begun 15 Days Following the Burn 


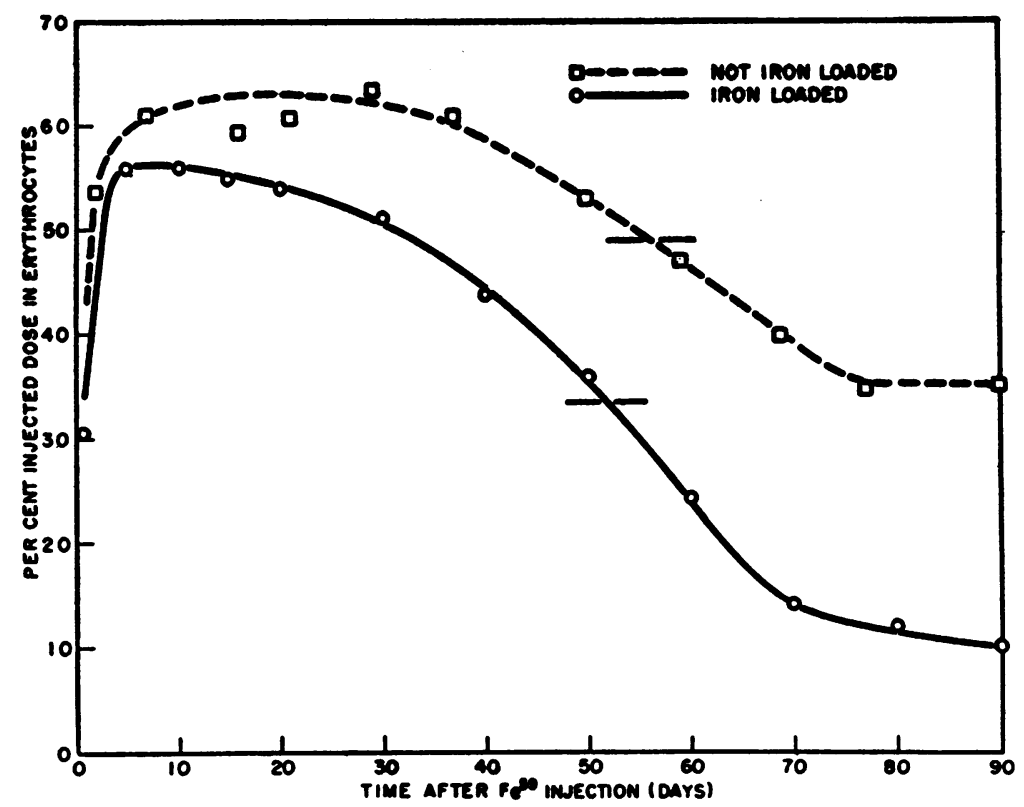

Fig. 7. Comparative Erythrocyte Disappearance Curves for Unburned Antyals which Have Expanded (Iron Loaded) Iron Stores and Norkal (nor Iron LOADED) Iron Stores

The horizontal dash indicates the points of 50 per cent destruction as calculated from the point of maximum uptake to the point of lowest stable radioactivity. The "not iron loaded" curve represents the mean of six animals while the "iron loaded" curve represents the mean of eight animals.

In Table I are shown the estimated mean life spans for the various control and treated groups. A shortened erythrocyte survival time was characteristic of burned animals from the second through the fifteenth day after burning. The pattern of destruction in the burned rats was characterized by immediate rapid destruction of erythrocytes in a random fashion not preceded by a period of aging. The high initial slope of the

TABLE I

Measurement of erythrocyte life span in control and burned animals

\begin{tabular}{|c|c|c|c|c|}
\hline \multirow[b]{2}{*}{$\begin{array}{c}\text { Time of } \mathrm{Fe} \\
\text { injection }\end{array}$} & \multicolumn{2}{|c|}{ Control } & \multicolumn{2}{|c|}{ Burned } \\
\hline & $\begin{array}{l}\text { Life } \\
\text { span }\end{array}$ & Mean & $\begin{array}{l}\text { Life } \\
\text { epan }\end{array}$ & Mean \\
\hline 2 days post burn & $\begin{array}{l}49 \\
53 \\
54\end{array}$ & 51 & $\begin{array}{l}26 \\
33 \\
35\end{array}$ & 31 \\
\hline 7 days post burn & $\begin{array}{l}56 \\
46\end{array}$ & 51 & $\begin{array}{l}33 \\
25\end{array}$ & 29 \\
\hline 15 days post burn & $\begin{array}{l}54 \\
54 \\
45\end{array}$ & 51 & $\begin{array}{l}26 \\
25 \\
24\end{array}$ & 25 \\
\hline
\end{tabular}

destruction curve implies that the maximal utilization in the absence of destruction would be in excess of the observed values.

Figure 7 is a plot of the erythrocyte survival curves for eight control animals treated with saccharated iron oxide and for six control animals not given intravenous iron for the purposes of expanding iron stores. The principal effect of enlarging the iron pool by intravenous inorganic iron is to lower the eventual stable level to which the specific activity of the erythrocytes fall. In spite of the relatively small decline in radioactivity in those animals not given intravenous iron, the estimate of the mean erythrocyte survival time is essentially the same as for those animals with an expanded iron pool.

\section{DISCUSSION}

Previous observations in this laboratory (4) have shown the immediate reduction in circulating red cell volume following high intensity radiant energy thermal burns in the rat, and the subse- 
quent return of the red cell volume toward normal values. Following the period of initial reduction in red cell volume which most probably represents removal of heat damaged erythrocytes, the rapid replacement of the lost red cell volume is accompanied by a sustained reticulocytosis, and an elevated resistance of the erythrocytes to osmotic damage (4). Histological evidence of increased extramedullary as well as medullary hematopoiesis is also seen (4). This evidence is interpreted as indicative of accelerated replacement compensating for an active hemolytic process continuing long after the initial thermal trauma. In view of these findings it is not entirely unexpected that tracer doses of $\mathrm{Fe}^{59}$ are incorporated more rapidly in burned rats than in control animals.

On the basis of the large body of observations of radioiron utilization in a variety of conditions and diseases, it is possible to interpret variations in the rate of uptake and in the fraction of the injected dose utilized as the result of either altered rates of erythropoiesis (10) or change in the size of the available iron pool. Finch, Wolff, Rath, and Fluharty (8) have demonstrated the decreased level of radioiron utilization in hemochromatosis characterized by much enlarged stores of iron but a presumed normal rate of erythropoiesis. The opposite effect is seen in the anemia of iron deficiency where greatly augmented rates of radioiron utilization and levels of $\mathrm{Fe}^{59}$ incorporation are seen following tracer doses of $\mathrm{Fe}^{59}$. The fraction of the injected dose appearing in peripheral erythrocytes depends on three variables: (a) the rate of erythropoiesis; (b) the size of the labile iron pool; and (c) the rate at which radioactive iron is being deposited in poorly available iron stores. In the case of animals which are rapidly destroying red cells, as in the burned animals reported on here, another important factor must be considered. If red cells are being destroyed soon after production the apparent level of maximal incorporation will be reduced. As a result of these considerations, it is felt that the most useful criterion of rate of erythropoiesis is the slope of the initial uptake curve rather than the maximum level attained. As a measure of this slope the time required to reach one-half the maximum incorporation has been used. These values are shown in Table II. Although there is no a priori evidence that iron stores deviate greatly from
TABLE II

Relative rates and amounts of $F e^{\text {so }}$ incorporation in circulating erythrocytes in burned and untreated rats

\begin{tabular}{lcc}
\hline \hline $\begin{array}{c}\text { Experimental } \\
\text { group }\end{array}$ & $\begin{array}{c}\text { Mean } \\
\text { maximum } \\
\text { incorporation } \\
\text { (per cent) }\end{array}$ & $\begin{array}{c}\text { Time for half } \\
\text { maximum } \\
\text { incorporation } \\
\text { (doys) }\end{array}$ \\
\hline Control & $54(9) *$ & 0.76 \\
2 days post burn & $58(4)$ & 0.49 \\
7 days post burn & $65(3)$ & 0.37 \\
15 days post burn & $59(3)$ & 0.33
\end{tabular}

* Figure in parentheses indicates the number of animals included in each mean value.

normal following thermal injury, this point has not been adequately investigated. However, it is felt justifiable to conclude from the uptake curves that the observed increased rate of radioiron utilization reflects an accelerated rate of erythropoiesis, both medullary and extramedullary, in the burned rat. The greater variation in uptake in burned animals studied two days after the burn compared with the animals studied at later times after burning indicates that the accelerated rate of erythropoiesis occurring as a result of the burn is still a variable finding at this early time.

The studies of erythrocyte survival show that the mean erythrocyte life span in the burned rats is $27 \pm 4$ days compared to mean values of $51 \pm$ 5 days in the normal control animals. The values reported here confirm the mean erythrocyte life span of normal rats found by Burwell, Brickley, and Finch (9) to be 45 to 50 days, utilizing essentially the same method. They emphasize that in the rat the removal of red cells is essentially a random process occurring without regard for cell age. Their data, however, as well as those reported here, would seem to indicate a relatively slow random process during the first 30 days followed by a more rapid process of removal of older cells which is apparent in the period 30 to 60 days.

The findings here reported are interpreted to indicate that in rats the anemia of thermal injury is characterized both by increased rates of erythropoiesis and an accelerated continuing random destruction of red blood cells, i.e., active hemolysis. This hemolytic process is over and above the intravascular hemolysis occurring as an acute event during or immediately after the thermal injury itself. 
Moore, Peacock, Blakely, and Cope (1) report six measurements of radioiron utilization at scattered points in three severely burned human patients. In the first patient iron utilization measured at one month and three months following the burn was still depressed. In a second patient, measured on the first day after the burn, $\mathrm{Fe}^{55}$ uptake was severely depressed but two utilization measurements made several months later in the course of the patient's recovery were essentially normal. Iron uptake in the third patient on the fifth day of a massive burn, which proved fatal, was normal. Wintrobe, Greenberg, Humphreys, Ashenbrucker, Worth, and Kramer (5), in a study of the anemia of infection and inflammation in iron deficient pigs, report radioiron utilization in two burned animals. In one animal the radioiron uptake was greatly depressed below the preinjury determination; in the other animal the uptake was slightly greater than the preinjury utilization. No studies have been undertaken in pig or man to follow erythrocyte survival subsequent to the uptake period.

The group at the Medical College of Virginia $(2,3)$ has recently reported on the utilization of $\mathrm{N}^{15}$ glycine for red cell production in burned dogs and patients. They have concluded that the anemia of thermal burns is the result of an early hemolytic process followed by a period of dyshematopoiesis. Objections against this interpretation are that the fecal urobilinogen as well as the hemolytic index remained elevated for many days following injury in severely burned patients. This may be construed as evidence of a continuing hemolytic process. In addition it is entirely possible that depression in production of a remote precursor to hemoglobin might exist without depression of red cell formation. Tissue stores of the precursor could be used until exhausted.

\section{SUMMARY}

The anemia of thermal injury has been investigated in rats subjected to high intensity radiant energy thermal burns. Observations of $\mathrm{Fe}^{50}$ utilization following injection of tracer doses have been made in control and burned animals 2, 7, and 15 days after burning and indicate an accelerated rate of $\mathrm{Fe}^{50}$ uptake in burned animals. Utilizing heavy iron loading after the period of uptake to depress reutilization, these same labeled erythrocytes have been used for measurement of erythrocyte life span in the same control and burned animals. The mean erythrocyte life span of normal rats has been found to be 51 days; the mean erythrocyte life span of burned animals has been measured as 27 days. The burned animal shows early and continuing random destruction of erythrocytes at a rate greater than normal. This hemolytic process is compensated for in the rat by increased rates of medullary and extramedullary hematopoiesis and is indicated by the return to normal red cell volume and the sustained reticulocytosis seen following thermal injury.

\section{REFERENCES}

1. Moore, F. D., Peacock, W. C., Blakely, E., and Cope, O., The anemia of thermal burns. Ann. Surg., 1946, 124, 811.

2. James, G. W., III, Purnell, O. J., and Evans, E. I., The anemia of thermal injury. I. Studies of pigment excretion. J. Clin. Invest., 1951, 30, 181.

3. James, G. W., III, Abbott, L. D., Jr., Brooks, J. W., and Evans, E. I., The anemia of thermal injury. III. Erythropoiesis and hemoglobin metabolism studied with $\mathrm{N}^{15}$-glycine in dog and man. J. Clin. Invest., 1954, 33, 150.

4. Davis, A. K., Alpen, E. L., Sheline, G. E., and Davis, W. M., Combined effects of total body X irradiation and radiant energy thermal burns. II. Anemia. Ann. Surg., In press.

5. Wintrobe, M. M., Greenberg, G. R., Humphreys, S. R., Ashenbrucker, H., Worth, W., and Kramer, R., The anemia of infection. III. The uptake of radioactive iron in iron-deficient and pyridoxinedeficient pigs before and after acute inflammation. J. Clin. Invest., 1947, 26, 103.

6. Kuhl, P. R., Sheline, G. E., and Alpen, E. L., Strontium sulfide depilation of rat skin and the effect of lanolin on depilated skin. J. Lab. \& Clin. Med., 1953, 41, 913.

7. Sheline, G. E., Alpen, E. L., Kuhl, P. R., and Ahokas, A. J., Effects of high intensity radiant energy on skin. I. Type of injury and its relationship to energy delivery rate. Arch. Path., 1953, 55, 265.

8. Finch, C. A., Wolff, J. A., Rath, C. E., and Fluharty, R. G., Iron metabolism. Erythrocyte iron turnover. J. Lab. \& Clin. Med., 1949, 34, 1480.

9. Burwell, E. L., Brickley, B. A., and Finch, C. A., Erythrocyte life span in small animals. Comparison of two methods employing radioiron. Am. J. Physiol., 1953, 172, 718.

10. Hennessy, T. G., and Huff, R. L., Depression of tracer ion uptake curve in rat erythrocytes following total body X-irradiation. Proc. Soc. Exper. Biol. \& Med., 1950, 73, 436. 